\title{
Congenital Melanocytic Nevus
}

National Cancer Institute

\section{Source}

National Cancer Institute. Congenital Melanocytic Nevus. NCI Thesaurus. Code C3944.

A melanocytic nevus that is present at birth. It may present as a small macular, papular,

or plaque-like lesion or as a large brown to black hairy skin lesion. 